()

\title{
Neudesin in obesity and type 2 diabetes mellitus: the effect of acute fasting and weight reducing interventions
}

This article was published in the following Dove Medical Press journal:

Diabetes, Metabolic Syndrome and Obesity:Targets and Therapy

\author{
Helena Kratochvilova, ${ }^{1-3}$ \\ Zdenka Lacinova, ${ }^{1-3}$ \\ Jana Klouckova, ${ }^{1-3}$ \\ Petra Kavalkova, ${ }^{2,3}$ Anna \\ Cinkajzlova, ${ }^{1-3}$ Pavel \\ Trachta, ${ }^{4}$ Jarmila Krizova, ${ }^{4}$ \\ Marek Benes, ${ }^{5}$ Karin \\ Dolezalova, ${ }^{6}$ Martin Fried, ${ }^{6}$ \\ Zuzana Vlasakova, ${ }^{7}$ Terezie \\ Pelikanova, ${ }^{7}$ Julius Spicak, ${ }^{5}$ \\ Milos Mraz, ${ }^{2,3,7}$ Martin \\ Haluzik $^{1-3,7}$ \\ 'Centre for Experimental Medicine, \\ Institute for Clinical and Experimental \\ Medicine, Prague, Czech Republic; \\ ${ }^{2}$ Department of Medical Biochemistry \\ and Laboratory Diagnostics, First \\ Faculty of Medicine, Charles \\ University, Prague, Czech Republic; \\ ${ }^{3}$ Department of Medical Biochemistry \\ and Laboratory Diagnostics, General \\ University Hospital, Prague, Czech \\ Republic; ${ }^{4}$ Third Department \\ of Medicine, Department of \\ Endocrinology and Metabolism, \\ First Faculty of Medicine, Charles \\ University and General University \\ Hospital, Prague, Czech Republic; \\ ${ }^{5}$ Hepatogastroenterology Department, \\ Institute for Clinical and Experimental \\ Medicine, Prague, Czech Republic; \\ ${ }^{6}$ Department of Surgery, OB Clinic, \\ Prague, Czech Republic; ${ }^{7}$ Diabetes \\ Centre, Institute for Clinical and \\ Experimental Medicine, Prague, Czech \\ Republic
}

Correspondence: Martin Haluzik Centre for Experimental Medicine, Institute for Clinical and Experimental Medicine, Vídeňská 1958/9, 14021 Prague 4, Czech Republic Email martin.haluzik@ikem.cz
Context: Neudesin has recently been identified as a novel regulator of energy expenditure in experimental animals; however, its role in humans remains unexplored.

Objective: The aim of this study was to assess the effects of obesity and type 2 diabetes mellitus (T2DM) along with selected weight reducing interventions on serum neudesin levels and adipose tissue mRNA expression.

Patients and methods: Fifteen obese subjects with T2DM undergoing endoscopic duodenaljejunal bypass liner (DJBL) implantation, 17 obese subjects (11 with T2DM, 6 without T2DM) scheduled for gastric plication (GP), 15 subjects with functional hypoglycemia subjected to 72-hour acute fasting (AF), and 12 healthy controls were included in the study.

Results: Baseline neudesin levels were comparable between all groups. DJBL increased neudesin at 6 and 10 months after the procedure $(1.77 \pm 0.86$ vs $2.28 \pm 1.27$ vs $2.13 \pm 1.02 \mathrm{ng} / \mathrm{mL}, P=0.001$ for baseline vs 6 vs 10 months) along with reduction in body weight and improvement of $\mathrm{HbA}_{1 \mathrm{c}}$ without any effect on neudesin mRNA expression in subcutaneous adipose tissue. Conversely, GP did not affect neudesin levels despite marked reduction in body weight and improvement of $\mathrm{HbA}_{1 \mathrm{c}}$. In contrast, AF decreased neudesin levels during the entire period ( $1.74 \pm 0.54 \mathrm{vs} 1.46 \pm 0.48$ $\mathrm{ng} / \mathrm{mL}, P=0.001$ for baseline vs 72 hours) with no impact of subsequent re-alimentation on neudesin concentrations.

Conclusion: Neudesin levels are differentially regulated during AF and chronic weight reduction induced by DJBL or GP. Further studies are needed to assess its possible significance in energy homeostasis regulation in humans.

Keywords: neudesin, obesity, type 2 diabetes mellitus, bariatric surgery, acute fasting, weight reduction, energy homeostasis

\section{Introduction}

Increasing prevalence of obesity and its metabolic complications, in particular type 2 diabetes mellitus (T2DM), represents one of the most significant challenges of current health care systems. ${ }^{1,2}$ It is well known that the clustering of diabetes, obesity, and other comorbidities referred to as metabolic syndrome markedly increases the risk of chronic cardiovascular complications, thus impacting both quality of life and life expectancy of patients. ${ }^{3,4}$ Changes in the central nervous system (CNS) including disturbances of neuropeptides regulating energy homeostasis significantly contribute to the development of obesity and its complication. ${ }^{5-7}$ It is thus of utmost importance to better understand the factors involved in the central regulation of energy homeostasis.

Neudesin is a newly identified factor contributing to the complex control of energy homeostasis. ${ }^{8}$ It was originally identified in mice embryos as a secreted protein with 
neurotrophic activity. ${ }^{9}$ Neudesin is a member of the membrane-associated progesterone receptor family that consists of four proteins characterized by common cytochrome 5-like heme/steroid binding domain. Of this protein family, neudesin and neuferricin are secreted proteins, whereas two other members - progesterone receptor-membrane components 1 and 2 - are located on cell membranes. ${ }^{10}$ Human neudesin has a 172 amino acid sequence with high similarity to other vertebrates. ${ }^{9}$ Neudesin activates mitogen-activated protein kinase (MAPK) and phosphoinositide 3-kinase (PI3K) signaling pathways and has been shown to play a role in neural cell differentiation, cell proliferation, and tumorigenesis. ${ }^{8,11}$

Neudesin is preferentially expressed in the CNS and spinal cord where it promotes neural cell differentiation. ${ }^{12}$ In addition to neurotrophic effects, it can influence appetite control in the hypothalamus ${ }^{13}$ or anxious-like behavior controlled by the dentate gyrus of the hippocampus. ${ }^{14}$ Neudesin mRNA expression was also documented in other tissues including adipose tissue, heart, lungs, and kidney. ${ }^{13}$

Studies suggest that neudesin plays a multifaceted role mainly in neural function and energy metabolism regulation. ${ }^{12,15}$ Neudesin-knockout (KO) mice were resistant to high fat diet (HFD)-induced obesity and obesity-related metabolic dysfunctions. ${ }^{15}$ By contrast, acute intracerebroventricular administration of neudesin decreased food intake and body weight and these effects were attenuated in obese mice that were fed an HFD. ${ }^{13}$

Taken together, experimental studies suggest that neudesin could be a novel regulator of energy homeostasis and food intake with potential role in the development of obesity and its complications. As no data concerning changes in neudesin levels in humans are available, we tested the hypothesis that serum neudesin concentrations may be affected by obesity and T2DM. To this end, we measured serum neudesin levels and its mRNA expression in subcutaneous (SAT) and visceral adipose tissue (VAT) in obese subjects with or without T2DM. We also explored the effect of acute fasting (AF) and selected weight reducing interventions on neudesin levels and its relationship to anthropometric, metabolic, and hormonal parameters to gain more insight into its possible role in the development of obesity-related metabolic disturbances.

\section{Materials and methods}

\section{Study subjects and interventions}

Fifteen obese subjects with T2DM ( $\mathrm{n}=5 / 10$; female/male [f/m]) undergoing endoscopic duodenal-jejunal bypass liner (DJBL) implantation, 17 obese subjects (11 with T2DM [8/3; $\mathrm{f} / \mathrm{m}], 6$ without T2DM $[4 / 2 ; \mathrm{f} / \mathrm{m}])$ scheduled for bariatric surgery - gastric plication (GP), 15 subjects with functional hypoglycemia ( $\mathrm{n}=7 / 8 ; \mathrm{f} / \mathrm{m}$ ) subjected to 72-hour AF, and 12 healthy controls $(8 / 4 ; \mathrm{f} / \mathrm{m})$ were included in the study. Written informed consent was signed by all participants prior to enrollment. The study was approved by the Human Ethics Review Board, First Faculty of Medicine and General University Hospital, Prague, Czech Republic, and was performed in accordance with the guidelines proposed in the Declaration of Helsinki (2000) of the World Medical Association.

\section{Anthropometric examination, blood and adipose tissue sampling}

All subjects included in the study were measured and weighted, and their body mass index (BMI) was calculated. Blood samples for biochemical and hormonal measurements were taken after overnight fasting and were centrifuged for 10 minutes at $3,000 \times \mathrm{g}$ within 30 minutes after withdrawal. Aliquots were stored at $-80^{\circ} \mathrm{C}$.

Samples of SAT were obtained by needle aspiration biopsy from the abdominal region or from the laparoscopic channel or laparotomy in case of surgery after overnight fasting. In subjects undergoing bariatric surgery, VAT samples were taken from the abdominal cavity at the beginning of the procedure. Tissue samples were collected to $1 \mathrm{~mL}$ of RNAlater ${ }^{\circledR}$ reagent (Thermo Fisher Scientific, Waltham, MA, USA) and stored at $-80^{\circ} \mathrm{C}$ until further analysis.

\section{DJBL}

Fifteen obese subjects with T2DM were included in the DJBL treatment group. Patient visits were conducted at baseline - before DJBL insertion (V1) and 1 (V2), 6 (V3), and 10 months (V4) after the implantation of DJBL. Anthropometric, serum biochemical, and hormonal parameters were measured and SAT samples were collected at each visit.

\section{Bariatric surgery}

Seventeen obese subjects ( 11 with T2DM, 6 without T2DM) underwent GP. Anthropometric measurements and blood and SAT samples were taken at baseline (V1), 6 (V3), and 12 months (V4b) after surgery. In addition to SAT obtained during each visit, samples of SAT and VAT were taken during surgery for the evaluation of depot-specific differences.

\section{Fasting in subjects with functional hypoglycemia}

Fifteen subjects with suspected hypoglycemic episodes underwent a supervised 72-hour fasting test to rule out organic hyperinsulinism, all of them with negative results. Serum neudesin 
was measured at the beginning (T1), at 24 (T2) and 48 hours (T3) of fasting, at the end of fasting (ie, after 72 hours - T4), and at 2 hours after re-alimentation (T5).

\section{Hormonal and biochemical assays}

Serum neudesin levels were measured by sandwich enzyme immunoassays using a commercial ELISA kit (Neudesin Human ELISA, BioVendor, Brno, Czech Republic). The assays including serum dilution were carried out according to the manufacturer's protocol. Sensitivity was $0.01 \mathrm{ng} / \mathrm{mL}$. Serum leptin concentrations were measured by the commercial ELISA kit (BioVendor). Sensitivity was $0.2 \mathrm{ng} / \mathrm{mL}$. Serum C-reactive protein levels (hsCRP) were measured by high-sensitive ELISA (Bender Medsystems, Vienna, Austria) with a sensitivity of $3 \mathrm{pg} / \mathrm{mL}$. Insulin concentrations were measured by RIA kit (Cis Bio International, France). Sensitivity was $2.0 \mu \mathrm{IU} / \mathrm{mL}$. The intra- and inter-assay variabilities were $<5.0 \%$ and $10.0 \%$, respectively.

Biochemical parameters (blood glucose, $\mathrm{HbA}_{1 \mathrm{c}}$, total and HDL cholesterol, and triglycerides) were measured and LDL cholesterol was calculated by standard laboratory methods at the Department of Biochemistry, General University Hospital, Prague, Czech Republic.

\section{Quantitative real-time PCR}

SAT and VAT samples were homogenized on MagNA Lyser Instrument (Hoffman-La Roche Ltd, Basel, Switzerland). Total RNA from homogenized tissue was extracted on a MagNA Pure instrument using a MagNa Pure Compact RNA Isolation kit (tissue) (Hoffman-La Roche Ltd). RNA concentration was determined from absorbance at $260 \mathrm{~nm}$ on a NanoPhotometer (Implen, Munchen, Germany). Reverse transcription was performed using random primers according to the manufacturer's protocol of the High-Capacity cDNA Reverse Transcription Kits (Thermo Fisher Scientific). The input amount of RNA was $0.25 \mu \mathrm{g}$ per reaction. Gene expression was performed on a ViiA 7 Real-Time PCR System (Thermo Fisher Scientific). For reaction, a mixture of TaqMan ${ }^{\circledR}$ Universal PCR Master Mix II, NO AmpErase ${ }^{\circledR}$ UNG (Thermo Fisher Scientific), nucleasefree water (Fermentas Life Science, Vilnius, Lithuania), and specific TaqMan ${ }^{\circledR}$ Gene Expression Assays (Thermo Fisher Scientific) were used. Beta-2 microglobulin was applied as endogenous reference. The formula $2^{-\mathrm{ddCt}}$ was used to calculate the relative gene expression.

\section{Statistical analysis}

Statistical analysis was performed using SigmaPlot 13.0 software (SPSS Inc., Chicago, IL, USA). Anthropometric, biochemical, and hormonal results are expressed as mean \pm
SD for parametric data or median (interquartile range) for nonparametric data. One-way ANOVA/one-way repeated measures (RM) ANOVA followed by Holm-Sidak test, one-way ANOVA on ranks/one-way RM ANOVA on ranks followed by Dunn's method, unpaired $t$-test or Mann-Whitney rank sum test, and paired test or Wilcoxon signed-rank test were used for the assessment of intergroup differences, as appropriate. Spearman or Pearson correlation test was used to calculate the relationships between serum neudesin and mRNA expression and other parameters. Combined groups of all study subjects with age-matched control subjects were used for correlation analysis. Statistical significance was considered at $P<0.05$.

\section{Results DJBL}

Anthropometric, biochemical, and hormonal characteristics are shown in Table 1. At baseline, patients with T2DM had higher BMI, blood glucose, $\mathrm{HbA}_{1 \mathrm{c}}$, CRP, triglycerides, insulin and leptin levels, and lower HDL cholesterol compared to healthy study control subjects. DJBL decreased BMI, improved glucose control and lipid profile, and reduced the levels of insulin and leptin compared to baseline (Table 2).

GP

At baseline, all subjects undergoing GP had higher BMI, leptin level, and CRP and reduced HDL cholesterol compared to control subjects, while T2DM patients had also increased blood glucose and $\mathrm{HbA}_{1 \mathrm{c}}$ (Tables 1 and 3). GP reduced anthropometric parameters and leptin levels and increased HDL cholesterol in both obese and T2DM subjects. In addition, T2DM subjects had lower $\mathrm{HbA}_{1 \mathrm{c}}$, while obese subjects without T2DM had decreased triglycerides and CRP after the procedure (Table 3 ).

\section{Functional hypoglycemia - AF test}

Patients with functional hypoglycemia undergoing the AF test for 72 hours had comparable baseline fasting blood glucose and lipid levels and anthropometric parameters relative to the control subjects (Table 1).

\section{Effect of interventions on serum neudesin levels and adipose tissue mRNA expression}

At baseline, all obese subjects with and without T2DM undergoing GP or DJBL implantation, as well as subjects with functional hypoglycemia, had comparable serum neudesin levels with healthy control subjects (Table 1). 
Table I Anthropometric and biochemical characteristics of study subjects at baseline

\begin{tabular}{|c|c|c|c|c|c|}
\hline \multirow[t]{2}{*}{ Group } & \multirow[t]{2}{*}{ DJBL } & \multicolumn{2}{|l|}{ GP } & \multirow[t]{2}{*}{ AF } & \multirow[t]{2}{*}{ Controls } \\
\hline & & T2DM+ & T2DM- & & \\
\hline Subjects (n) (female/male) & $15(5 / 10)$ & II (8/3) & $6(4 / 2)$ & $15(7 / 8)$ & $12(8 / 4)$ \\
\hline Age (years) & $50.5 \pm 10.3$ & $51.5 \pm 8.22$ & $49.2 \pm 11.8$ & $45.7 \pm 12.7$ & $43.2 \pm 9.51$ \\
\hline Body mass index $\left(\mathrm{kg} / \mathrm{m}^{2}\right)$ & $42.8 \pm 6.50^{\mathrm{a}}$ & $43.2 \pm 4.87^{\mathrm{a}}$ & $40.3 \pm 5.43^{\mathrm{a}}$ & $26.5 \pm 7.20^{b-d}$ & $24.2 \pm 1.86$ \\
\hline Blood glucose $(\mathrm{mmol} / \mathrm{L})$ & $11.4 \pm 3.34^{\mathrm{a}}$ & $9.27 \pm 3.11^{\mathrm{a}}$ & $5.23 \pm 0.83^{b}$ & $5.16 \pm 1.07^{b}$ & $4.58 \pm 0.58$ \\
\hline $\mathrm{HbA}_{\mathrm{Ic}}(\mathrm{mmol} / \mathrm{mol})$ & $73.4 \pm 17.1^{\mathrm{a}}$ & $60.1 \pm 16.2^{\mathrm{a}}$ & $37.3 \pm 5.09$ & $\mathrm{NP}$ & $33.2 \pm 4.09$ \\
\hline Cholesterol (mmol/L) & $4.58 \pm 0.87$ & $4.70 \pm 1.13$ & $5.65 \pm 3.12$ & $5.12 \pm 0.74$ & $5.12 \pm 1.22$ \\
\hline Triglycerides $(\mathrm{mmol} / \mathrm{L})$ & $1.32(1.22-2.37)^{\mathrm{a}}$ & $1.36(0.94-2.22)$ & $1.5 \mid(0.69-7.13)$ & $0.94(0.73-1.33)$ & $0.79(0.64-1.15)$ \\
\hline HDL cholesterol $(\mathrm{mmol} / \mathrm{L})$ & $1.12 \pm 0.2 \mathrm{I}^{\mathrm{a}}$ & $1.21 \pm 0.25^{\mathrm{a}}$ & $1.17 \pm 0.16^{\mathrm{a}}$ & NP & $1.76 \pm 0.36$ \\
\hline LDL cholesterol (mmol/L) & $2.91 \pm 1.02$ & $2.72 \pm 0.89$ & $2.66 \pm 0.48$ & NP & $2.94 \pm 1.13$ \\
\hline Insulin (mIU/L) & $66.8(38 . I-204)^{\mathrm{a}}$ & $53(30.2-63.7)^{\mathrm{a}}$ & $31.5(19.2-90.0)$ & $24.2(19.7-43)^{\mathrm{b}}$ & $18.8(9.08-22.4)$ \\
\hline Leptin $(\mathrm{ng} / \mathrm{mL})$ & $23.7 \pm 12.5^{\mathrm{a}}$ & $38.7 \pm 16.6^{a}$ & $24.6 \pm 16.9^{a}$ & $10.5 \pm 8.60^{\mathrm{b}, \mathrm{c}}$ & $10.3 \pm 6.28$ \\
\hline $\mathrm{CRP}(\mathrm{mg} / \mathrm{L})$ & $2.72(1.79-3.78)^{\mathrm{a}}$ & $1.27(0.48-3.03)^{\mathrm{a}}$ & $1.84(1.4 \mathrm{I}-3.78)^{\mathrm{a}}$ & $0.22(0.12-0.50)$ & $0.25(0.17-0.62)$ \\
\hline Neudesin mRNA expression in SAT & $1.12 \pm 0.53$ & $0.99 \pm 0.21$ & $1.11 \pm 0.19$ & $\mathrm{NP}$ & NP \\
\hline Serum neudesin $(\mathrm{ng} / \mathrm{mL})$ & $1.77 \pm 0.86$ & $2.27 \pm 0.75$ & $2.62 \pm 0.98$ & $1.74 \pm 0.54$ & $\mathrm{I} .87 \pm 0.70$ \\
\hline
\end{tabular}

Notes: Normally distributed data are shown as mean $\pm S D$, nonparametric data as median (interquartile range). ${ }^{a} P<0.05$ vs control; ${ }^{b}<<0.05$ vs $D J B L ; ~ C P<0.05$ vs $G P$ T2DM+; ${ }^{d} P<0.05$ vs GP T2DM-. Statistical significance is from one-way ANOVA.

Abbreviations: DJBL, duodenal-jejunal bypass liner; GP, gastric plication; AF, acute fasting; T2DM, type 2 diabetes mellitus; NP, non-measured parameter; CRP, C-reactive protein; SAT, subcutaneous adipose tissue.

Table 2 Effect of endoscopic DJBL on anthropometric, biochemical, and hormonal characteristics

\begin{tabular}{|c|c|c|c|c|c|}
\hline Group & Controls & VI & V2 & V3 & V4 \\
\hline Subjects (n) & 12 & 15 & 15 & 15 & 15 \\
\hline Age (years) & $43.2 \pm 9.51$ & $50.5 \pm 10.3$ & NP & NP & NP \\
\hline Body mass index $\left(\mathrm{kg} / \mathrm{m}^{2}\right)$ & $24.2 \pm 1.86$ & $42.7 \pm 6.53^{\mathrm{a}}$ & $40.5 \pm 6.92^{\mathrm{a}, \mathrm{b}}$ & $37.5 \pm 5.55^{\mathrm{a}-\mathrm{c}}$ & $36.5 \pm 4.9 \mathrm{I}^{\mathrm{a}-\mathrm{c}}$ \\
\hline Waist circumference $(\mathrm{cm})$ & $83.3 \pm 8.94$ & $|3| \pm \mid 4.5$ & $127 \pm 12.8^{\mathrm{b}}$ & $|20 \pm| \mid .8^{\mathrm{b}, \mathrm{c}}$ & $118 \pm 11.7^{b, c}$ \\
\hline Hip circumference $(\mathrm{cm})$ & $98.6 \pm 9.09$ & $13 \mid \pm 17.4$ & $127 \pm 16.7$ & $122 \pm 12.7^{b}$ & $120 \pm|| .5^{\mathrm{b}, \mathrm{c}}$ \\
\hline Blood glucose $(\mathrm{mmol} / \mathrm{L})$ & $4.58 \pm 0.58$ & $11.4 \pm 3.34^{\mathrm{a}}$ & $8.98 \pm 3.10^{\mathrm{a}, \mathrm{b}}$ & $8.47 \pm 2.19^{a, b}$ & $7.09 \pm 1.86^{\mathrm{a}, \mathrm{b}}$ \\
\hline $\mathrm{HbA}_{\mathrm{Ic}}(\mathrm{mmol} / \mathrm{mol})$ & $33.2 \pm 4.09$ & $73.4 \pm 17.1^{\mathrm{a}}$ & $63.8 \pm 15.9^{a, b}$ & $52.4 \pm 11.2^{\mathrm{a}, \mathrm{b}}$ & $50.0 \pm 12.6^{a-c}$ \\
\hline Cholesterol (mmol/L) & $5.12 \pm 1.22$ & $4.58 \pm 0.87$ & $3.97 \pm 0.60^{\mathrm{a}, \mathrm{b}}$ & $4.29 \pm 0.73$ & $3.86 \pm 0.73^{\mathrm{a}, \mathrm{b}}$ \\
\hline Triglycerides (mmol/L) & $0.79(0.64-1.15)$ & $1.32(1.22-2.37)^{\mathrm{a}}$ & $1.34(1.13-1.86)^{\mathrm{a}}$ & $1.39(1.10-2.00)^{\mathrm{a}}$ & $1.07(0.84-1.92)^{\mathrm{b}}$ \\
\hline HDL cholesterol (mmol/L) & $1.76 \pm 0.36$ & $1.12 \pm 0.2 \mathrm{I}^{\mathrm{a}}$ & $1.01 \pm 0.15^{\mathrm{a}, \mathrm{b}}$ & $1.09 \pm 0.18^{\mathrm{a}}$ & $1.07 \pm 0.28^{\mathrm{a}}$ \\
\hline LDL cholesterol (mmol/L) & $2.94 \pm 1.13$ & $2.91 \pm 1.02$ & $2.3 \mathrm{I} \pm 0.63^{\mathrm{b}}$ & $2.48 \pm 0.65$ & $2.15 \pm 0.64^{b}$ \\
\hline Insulin (mIU/L) & $18.8(9.08-22.4)$ & $66.8(38.1-204)^{\mathrm{a}}$ & $46.1(30.8-207)^{\mathrm{a}}$ & $51.4(38.0-234)^{\mathrm{a}}$ & $59.7(24.3-213)^{\mathrm{a}}$ \\
\hline Leptin $(\mathrm{ng} / \mathrm{mL})$ & $10.3 \pm 6.28$ & $23.7 \pm 12.5^{\mathrm{a}}$ & $|8.6 \pm 8.9|$ & $18.9 \pm 13.4$ & $|7.1 \pm 1| .4$ \\
\hline CRP (mg/L) & $0.25(0.17-0.62)$ & $2.72(1.79-3.78)^{\mathrm{a}}$ & $2.48(1.59-3.6)^{\mathrm{a}}$ & $1.67(1.44-3.95)^{\mathrm{a}}$ & $1.76(1.18-2.23)^{\mathrm{a}}$ \\
\hline Neudesin mRNA expression in SAT & NP & $1.12 \pm 0.53$ & NP & $1.08 \pm 0.39$ & $1.13 \pm 0.43$ \\
\hline
\end{tabular}

Notes: Normally distributed data are shown as mean $\pm S D$ and nonparametric data as median (interquartile range). ${ }^{p}<0.05$ vs controls, one-way ANOVA/ANOVA on ranks;

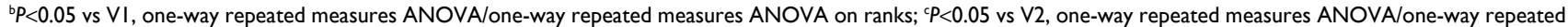
measures ANOVA on ranks.

Abbreviations: NP, non-measured parameter; DJBL, duodenal-jejunal bypass liner; CRP, C-reactive protein; SAT, subcutaneous adipose tissue; VI, before DJBL; V2, I month after DJBL; V3, 6 months after DJBL; V4, 10 months after DJBL.

DJBL increased neudesin levels after 6 months relative to baseline and the levels remained elevated 10 months after implantation (Figure 1). GP had no effect on serum neudesin (Figure 2). Patients with functional hypoglycemia had decreased neudesin levels after 48 and 72 hours of fasting as well as 2 hours after partial re-alimentation compared to the baseline and control group (Figure 3).
Neudesin mRNA expression in SAT was not affected by weight reduction and did not show any correlation with serum neudesin levels. There was no difference in baseline neudesin mRNA expression between SAT and VAT in subjects undergoing GP (Figure 4). A temporarily higher neudesin mRNA expression in SAT was observed in obese patients without T2DM relative to those with T2DM at 6 months after GP (Figure 4). 


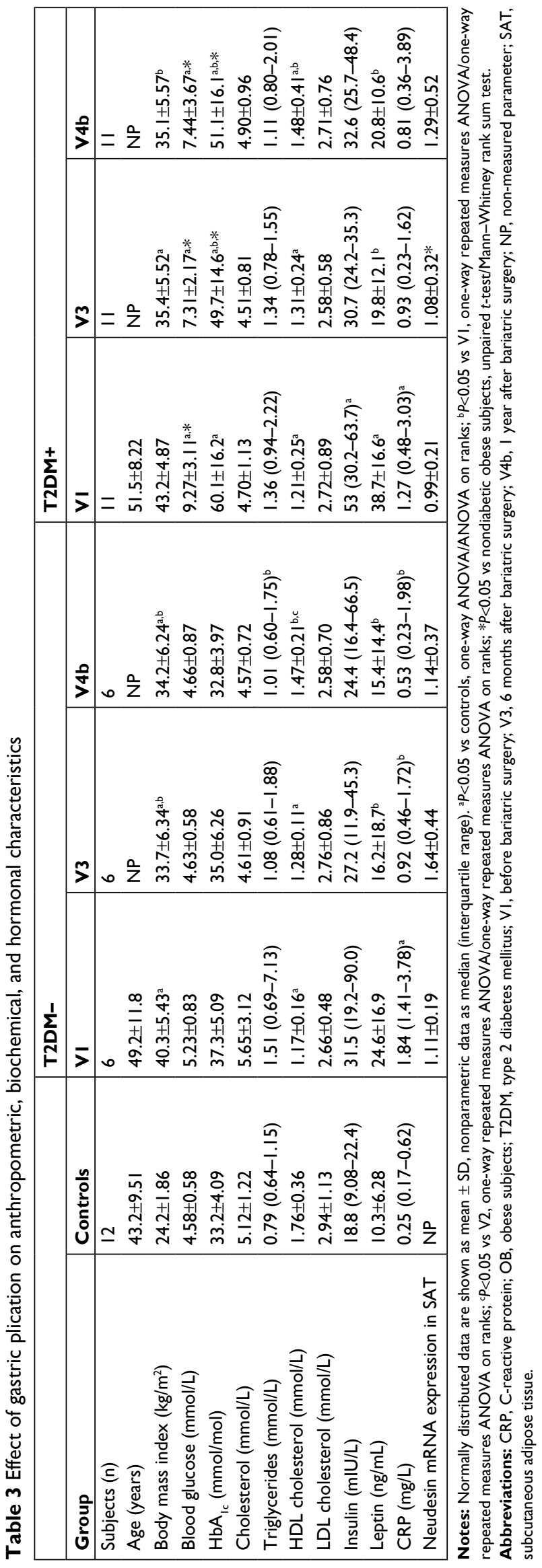

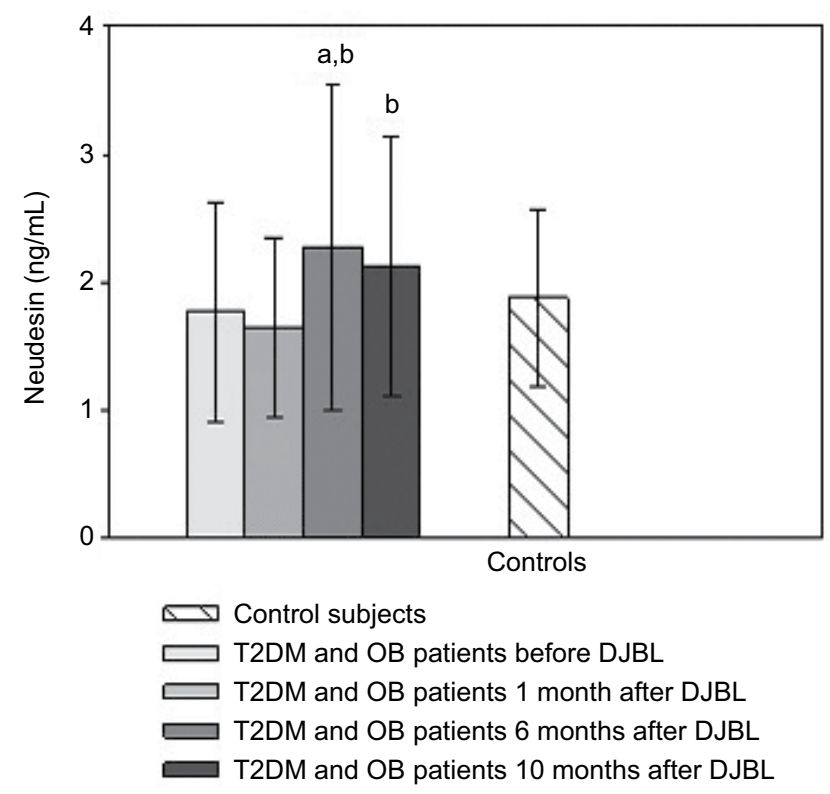

Figure I Serum neudesin levels: the effect of DJBL.

Notes: Values are mean \pm SD. Statistical significance is from one-way repeated measures ANOVA. ${ }^{\mathrm{a}} \mathrm{P}<0.05$ vs $\mathrm{VI}$. ${ }^{\mathrm{b}} \mathrm{P}<0.05$ vs $\mathrm{V} 2$.

Abbreviations: $O B$, obese subjects; T2DM, type 2 diabetes mellitus; DJBL, duodenal-jejunal bypass liner; VI, before DJBL; V2, I month after DJBL; V3, 6 months after DJBL; V4, 10 months after DJBL.

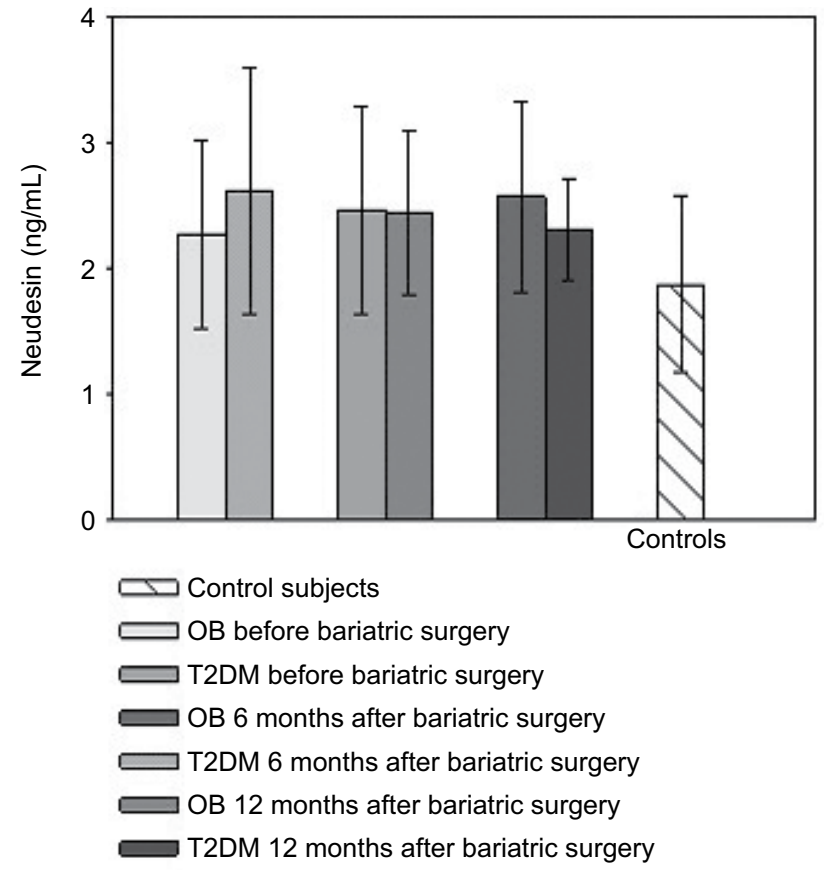

Figure 2 Serum neudesin levels: the effect of gastric plication.

Note: Values are mean \pm SD

Abbreviations: $O B$, obese subjects; T2DM, type 2 diabetes mellitus.

\section{Relationship of neudesin to other parameters}

Serum neudesin levels positively correlated with insulin levels $(R=0.434, P=0.001)$ and inversely with BMI $(R=-0.314$, 


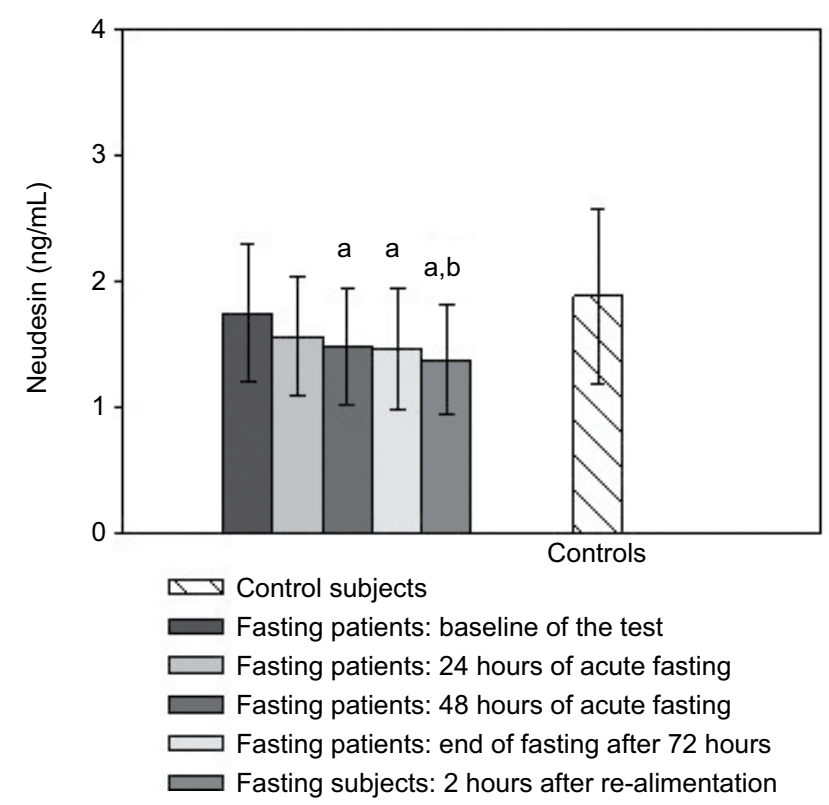

Figure 3 Serum neudesin levels: the effect of acute fasting.

Notes: Values are mean \pm SD. Statistical significance is from one-way repeated measures ANOVA. ${ }^{a} P<0.05$ vs baseline. ${ }^{b} P<0.05$ vs control subjects.

$P=0.016)$ in patients undergoing DJBL and with BMI $(R=-0.770, P=0.009)$ and insulin levels $(R=-0.579, P=0.002)$ in subjects undergoing the AF test. There was a positive correlation between neudesin mRNA expression in SAT and $\mathrm{HbA}_{1 \mathrm{c}}(R=0.398, P=0.014)$ in DJBL subjects.

Neudesin levels inversely correlated with CRP $(R=-0.396$, $P=0.006)$ in obese subjects with/without T2DM in the GP group, while negative correlation of neudesin levels with $\mathrm{HbA}_{1 \mathrm{c}}(R=-0.501, P=0.034)$ was observed in obese patients with T2DM. Neudesin mRNA expression in SAT was inversely related to BMI $(R=-0.352, P=0.041)$ and blood glu$\operatorname{cose}(R=-0.424, P=0.013)$ across the groups undergoing GP.

\section{Discussion}

Neudesin is a novel neurotrophic factor originally identified in the CNS with multiple functions in organisms including regulation of food intake and energy homeostasis, behavior, and sympathetic activity. ${ }^{9}$ Similar to other hypothalamic neuropeptides that play a role in food intake and energy metabolism regulation, ${ }^{16}$ neudesin is also produced in numerous peripheral tissues including adipose tissue, heart, lung, and kidney. ${ }^{8,17}$ Experimental studies showed that neudesin-KO mice were resistant to diet-induced obesity and obesity-related metabolic dysfunction ${ }^{15}$ owing to increased sympathetic nervous activity with subsequent augmentation of energy expenditure, lipolysis in white adipose tissue, and heat production and free fatty acid oxidation in brown adipose tissue. ${ }^{15}$ Interestingly, another study by Byerly et al ${ }^{13}$ showed that intracerebroventricular administration of recombinant neudesin decreased food intake and body weight suggesting its complex role in the regulation of energy homeostasis with potential differences in peripheral and central effects. Furthermore, neudesin administration was only efficacious in lean mice while its effects on food intake were blunted in obese mice that were fed an HFD. ${ }^{13}$

To the best of our knowledge, no data describing changes of circulating neudesin levels and its possible significance in the regulation of energy homeostasis in humans are available. In our study, baseline serum neudesin concentrations in obese subjects both with and without T2DM did not differ from healthy lean control subjects. To gain further insight into the dynamic regulation of serum neudesin concentrations we explored the influence of three interventions affecting energy homeostasis. In obese diabetic patients undergoing DJBL implantation circulating neudesin concentrations significantly increased 6 months after its insertion and remained elevated until month 10 when DJBL was removed. It is important to note that DJBL implantation led to a marked body weight loss and improvement of glucose control suggesting a possible interconnection of increased neudesin levels with these changes. This was further corroborated by the positive correlation between neudesin and serum insulin, which is especially interesting with regard to their common effector pathway including the activation of MAPK and PI3K signaling cascades. ${ }^{8,18}$ Nevertheless, the universality of a direct relationship between neudesin and metabolic state was not confirmed by our other data from obese diabetic subjects undergoing bariatric surgery. These patients, similar to DJBL patients, experienced marked weight loss and improvement in glucose control but their serum neudesin levels remained unchanged throughout the 12-month follow-up period. Finally, AF in nonobese individuals decreased neudesin levels again pointing out to its possible interconnection with energy homeostasis.

Adipose tissue has been described as one of the sources of neudesin in mice. ${ }^{19}$ To this end, we explored neudesin mRNA expression in patients undergoing bariatric surgery. Although we did not detect any differences between SAT and VAT neudesin mRNA expression, we found a transient increase in neudesin mRNA expression in SAT 6 months after GP in obese patients without T2DM, while no such change was detected in obese diabetics. Interestingly, these data differ from experimental results showing increased neudesin mRNA expression in white adipose tissue of mice that were fed an HFD. ${ }^{15}$ Using cultured 3T3-L1 preadipocytes, Kimura et $\mathrm{al}^{19}$ described suppression of adipogenesis 

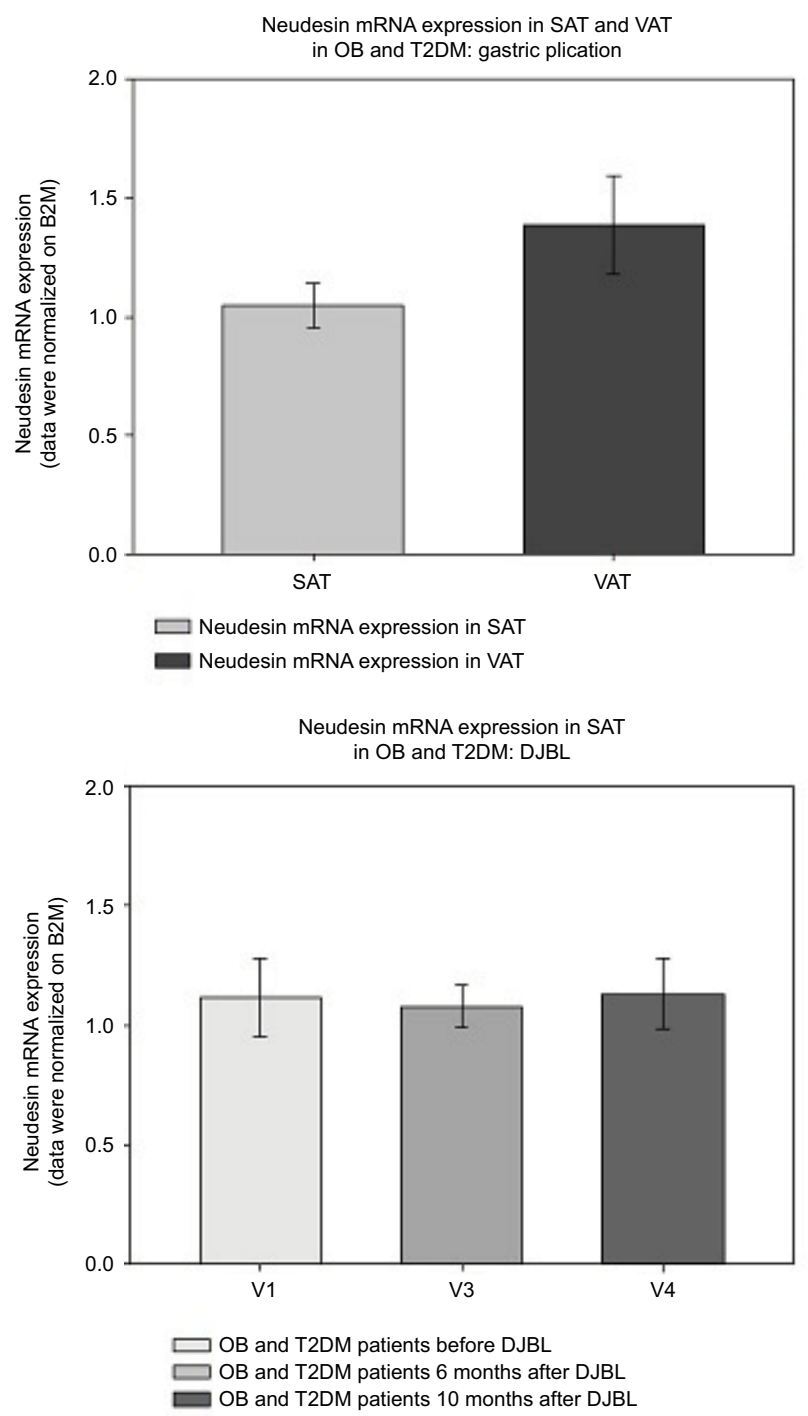

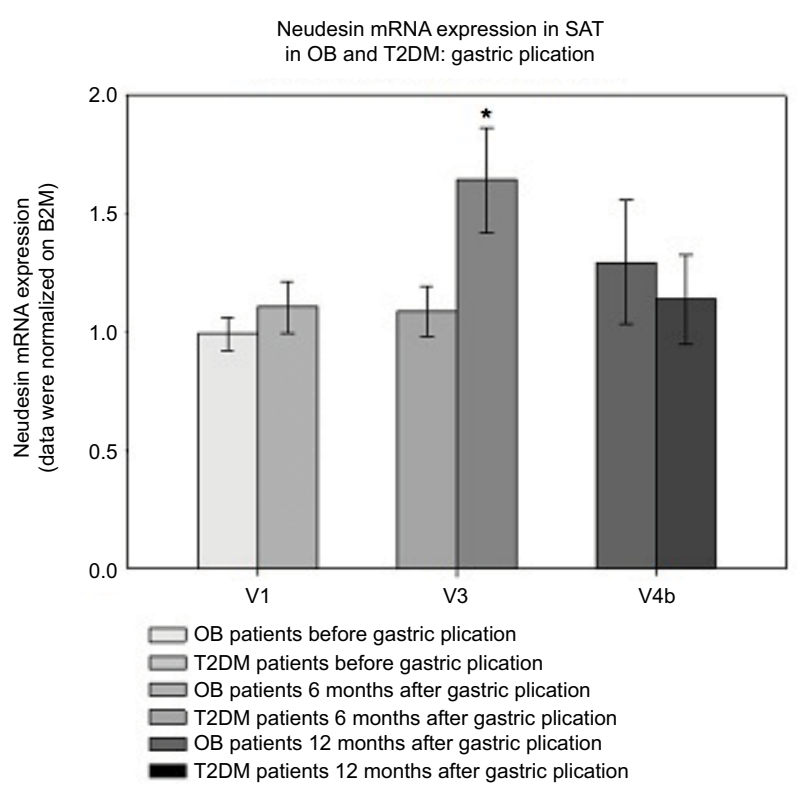

Neudesin mRNA expression in SAT

Figure 4 Neudesin mRNA expression in SAT and VAT during GP and DJBL.

Notes: Values are mean \pm SD. Statistical significance is from unpaired $t$-test (OB vs T2DM). $* P<0.05$ vs $O B$ group.

Abbreviations: DJBL, duodenal-jejunal bypass liner; OB, obese patients; T2DM, type 2 diabetes mellitus; VI, before intervention; V3, 6 months after intervention; V4, I0 months after intervention; V4b, 12 months after intervention; SAT, subcutaneous adipose tissue; VAT, visceral adipose tissue; GP, gastric plication; B2M, beta-2 microglobulin.

induced by increased neudesin mRNA expression. It is thus plausible that this transient increase in adipose tissue neudesin mRNA expression could be connected to changes in adipogenesis induced by weight loss after bariatric surgery. Further studies are certainly needed to verify such a possible interconnection. ${ }^{19}$

As our study is the first to describe changes in circulating neudesin levels in humans, caution is necessary in data interpretation. Firstly, we measured circulating levels of neudesin that are very likely of peripheral origin and may not reflect its changes in the CNS. Currently, no experimental data with peripheral neudesin administration are available and it is thus not possible to conclude if actions of neudesin in peripheral tissues can contribute to the improvements after DJBL. Importantly, in our study, neudesin levels were increased only after DJBL but not after GP (a restrictive-type bariatric procedure) despite comparable drop in body weight and improvement in glucose control after both interventions. These findings suggest that changes in the gastrointestinal tract induced by DJBL, eg, duodenal exclusion, modulation of bile acids or other DJBL-specific effects that are not present in patients after $\mathrm{GP}^{20,21}$ could have contributed to increased serum neudesin levels. Decreased neudesin concentrations after $\mathrm{AF}$ point out to possible differences in the regulation of neudesin under acute vs chronic interventions decreasing food intake. The obtained data do not enable us to explain 
the different trends between serum neudesin levels and its mRNA expression in SAT with increased expression in obese GP subjects and no change in DJBL individuals; the findings nevertheless suggest that adipose tissue is not the primary source of systemic neudesin and that, in addition to increased adiposity, diabetic state might play a role in local adipose tissue regulation of neudesin production.

Taken together, serum neudesin levels increased after DJBL implantation in obese patients with T2DM and decreased after AF in nonobese subjects. On the other hand, serum neudesin was not affected by the restrictivetype bariatric procedure of GP. Overall, our data suggest a complex interconnection between changes in energy homeostasis and circulating neudesin concentrations with distinct effects of acute vs chronic energy restriction and differential influence of procedures affecting different parts of the digestive tract.

\section{Acknowledgments}

An abstract of this paper was presented at the American Diabetes Association (ADA) 78th Scientific Sessions, June 22-26, 2018, Orlando, FL, USA, and has been published. ${ }^{22}$ This study was supported by the Ministry of Health, Czech Republic - Conceptual Development of Research Organization ("Institute for Clinical and Experimental Medicine - IKEM, IN 00023001” and RVO VFN 64165).

\section{Disclosure}

The authors report no conflicts of interest in this work.

\section{References}

1. O'Rahilly S. Science, medicine, and the future. non-insulin dependent diabetes mellitus: the gathering storm. BMJ. 1997;314(7085):955-959.

2. Hruby A, Hu FB. The epidemiology of obesity: a big picture. Pharmacoeconomics. 2015;33(7):673-689.

3. Reaven G. Metabolic syndrome: pathophysiology and implications for management of cardiovascular disease. Circulation. 2002;106(3): 286-288.

4. Reaven G. Syndrome X. Curr Treat Options Cardiovasc Med. 2001;3(4): 323-332.
5. Seoane-Collazo P, Fernø J, Gonzalez F, et al. Hypothalamic-autonomic control of energy homeostasis. Endocrine. 2015;50(2):276-291.

6. Lau J, Herzog H. CART in the regulation of appetite and energy homeostasis. Front Neurosci. 2014;8:313.

7. Farooqi IS, O'Rahilly S. 20 years of leptin: human disorders of leptin action. $J$ Endocrinol. 2014;223(1):T63-T70.

8. Ohta H, Kimura I, Konishi M, Itoh N. Neudesin as a unique secreted protein with multi-functional roles in neural functions, energy metabolism, and tumorigenesis. Front Mol Biosci. 2015;2:24.

9. Kimura I, Yoshioka M, Konishi M, Miyake A, Itoh N. Neudesin, a novel secreted protein with a unique primary structure and neurotrophic activity. J Neurosci Res. 2005;79(3):287-294.

10. Kimura I, Nakayama Y, Konishi M, et al. Functions of MAPR (membrane-associated progesterone receptor) family members as heme/ steroid-binding proteins. Curr Protein Pept Sci. 2012;13(7):687-696.

11. Han KH, Lee SH, Ha SA, et al. The functional and structural characterization of a novel oncogene GIG47 involved in the breast tumorigenesis. BMC Cancer. 2012;12(1):274.

12. Kimura I, Nakayama Y, Zhao Y, Konishi M, Itoh N. Neurotrophic effects of neudesin in the central nervous system. Front Neurosci. 2013;7:111.

13. Byerly MS, Swanson RD, Semsarzadeh NN, et al. Identification of hypothalamic neuron-derived neurotrophic factor as a novel factor modulating appetite. Am J Physiol Regul Integr Comp Physiol. 2013;304(12):R1085-R1095.

14. Novais A, Ferreira AC, Marques F, et al. Neudesin is involved in anxiety behavior: structural and neurochemical correlates. Front Behav Neurosci. 2013;7:119.

15. Ohta H, Konishi M, Kobayashi Y, et al. Deletion of the neurotrophic factor neudesin prevents diet-induced obesity by increased sympathetic activity. Sci Rep. 2015;5:10049.

16. Sun WW, Zhu P, Shi YC, et al. Current views on neuropeptide Y and diabetes-related atherosclerosis. Diab Vasc Dis Res. 2017;14(4):277-284.

17. Schwartz MW, Woods SC, Porte D, Seeley RJ, Baskin DG. Central nervous system control of food intake. Nature. 2000;404(6778):661-671.

18. Saltiel AR, Kahn CR. Insulin signalling and the regulation of glucose and lipid metabolism. Nature. 2001;414(6865):799-806.

19. Kimura I, Konishi M, Asaki T, et al. Neudesin, an extracellular hemebinding protein, suppresses adipogenesis in 3T3-L1 cells via the MAPK cascade. Biochem Biophys Res Commun. 2009;381(1):75-80.

20. Haluzík M, Kratochvílová H, Haluzíková D, Mráz M. Gut as an emerging organ for the treatment of diabetes: focus on mechanism of action of bariatric and endoscopic interventions. $J$ Endocrinol. 2018;237(1): R1-R17.

21. Madsbad S, Dirksen C, Holst JJ. Mechanisms of changes in glucose metabolism and bodyweight after bariatric surgery. Lancet Diabetes Endocrinol. 2014;2(2):152-164.

22. Kratochvilova H, Lacinova Z, Klouckova J, et al. Neudesin, a Novel Regulator of Energy Metabolism in Obesity and Type 2 Diabetes Mellitus-The Effect of Acute Fasting and Endoscopic Duodenal-Jejunal Bypass Liner Implantation [abstract]. Diabetes. 2018;67(Supp1 1). Available from: http://diabetes.diabetesjournals.org/content/67/ Supplement_1/2449-PUB.
Diabetes, Metabolic Syndrome and Obesity: Targets and Therapy is an international, peer-reviewed open-access journal committed to the rapid publication of the latest laboratory and clinical findings in the fields of diabetes, metabolic syndrome and obesity research. Original research, review, case reports, hypothesis formation, expert opinion and commentaries are all considered for publication. The manuscript management system is completely online and includes a very quick and fair peer-review system, which is all easy to use. Visit http://www.dovepress.com/testimonials.php to read real quotes from published authors. 